\title{
Cystic Fibrosis with Meconium Ileus
}

National Cancer Institute

\section{Source}

National Cancer Institute. Cystic Fibrosis with Meconium Ileus. NCI Thesaurus. Code C103233.

A congenital metabolic detected in the neonatal period that is characterized by the presence of a meconium ileus. The disease affects the exocrine glands andis inherited as an autosomal trait. The secretions of exocrine glands are abnormal, resulting in excessively viscid mucus production which causes obstruction of passageways (including pancreatic and bile ducts, intestines, and bronchi). The sweat sodium and chloride content are increased. Symptoms usually appear in childhood and include meconium ileus, poor growth despite good appetite, malabsorption and foul bulky stools, chronic bronchitis with cough, recurrent pneumonia, bronchiectasis, emphysema, clubbing of the fingers, and salt depletion in hot weather. 